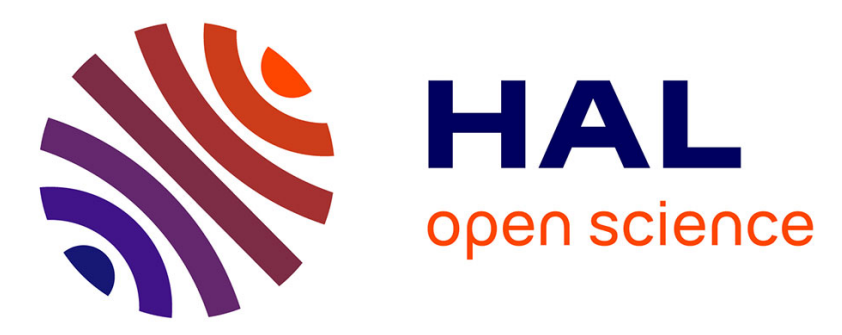

\title{
Fault Tolerant Control Strategy applied to PEMFC water management
}

\author{
Carole Lebreton, Michel Benne, Cédric Damour, Nadia Yousfi-Steiner, \\ Brigitte Grondin-Perez, Daniel Hissel, Jean-Pierre Chabriat
}

\section{To cite this version:}

Carole Lebreton, Michel Benne, Cédric Damour, Nadia Yousfi-Steiner, Brigitte Grondin-Perez, et al.. Fault Tolerant Control Strategy applied to PEMFC water management. International Journal of Hydrogen Energy, 2015, 40 (33), pp.10636-10646. 10.1016/j.ijhydene.2015.06.115 . hal-01221979

\section{HAL Id: hal-01221979 \\ https://hal.univ-reunion.fr/hal-01221979}

Submitted on 26 Oct 2016

HAL is a multi-disciplinary open access archive for the deposit and dissemination of scientific research documents, whether they are published or not. The documents may come from teaching and research institutions in France or abroad, or from public or private research centers.
L'archive ouverte pluridisciplinaire HAL, est destinée au dépôt et à la diffusion de documents scientifiques de niveau recherche, publiés ou non, émanant des établissements d'enseignement et de recherche français ou étrangers, des laboratoires publics ou privés. 


\title{
Fault Tolerant Control Strategy applied to PEMFC water management
}

\author{
Carole Lebreton ${ }^{a}$, Michel Benne ${ }^{a, *}$, Cédric Damour ${ }^{a}$, \\ Nadia Yousfi-Steiner ${ }^{b}$, Brigitte Grondin-Perez ${ }^{a}$, Daniel Hissel ${ }^{b}$, \\ Jean-Pierre Chabriat ${ }^{a}$ \\ ${ }^{a}$ LE2P, EA 4079, University of La Reunion, 15 Av. René Cassin, BP 7151, 97715 Saint-Denis, France \\ ${ }^{\mathrm{b}}$ FCLAB Research Federation, FR CNRS 3539, FEMTO-ST/Energy Department, UMR CNRS 6174, University of \\ Franche-Comté, Rue Thierry Mieg, 90010 Belfort Cedex, France
}

\begin{abstract}
A B S T R A C T
In this paper, a Fault Tolerant Control Strategy (FTCS) dedicated to PEMFC (Polymer Electrolyte Membrane Fuel Cell) water management is implemented and validated online on a real PEMFC system. Thanks to coupling a Fault Detection and Isolation (FDI), an adjustable controller and a reconfiguration mechanism, FTCS allows addressing the important challenge of Fuel Cell (FC) reliability improvement. Only few works have already been conducted on FTCS applied to FC actuators faults, and none of them on FC water management faults. In this work, a neural-based diagnosis tool is computed online as FDI component and is coupled to a self-tuning PID controller. This diagnosis tool shows low computational time and high detection performance. The self-tuning PID controller shows robustness against noise measurements and model uncertainties. Its low computational cost makes it a suitable control method for real-time FTCS. Performed on a PEMFC system, the FTCS shows promising results on fault diagnosis and performance recovery.
\end{abstract}

\section{Introduction}

Fuel cells (FC) are electro-chemical converters turning hydrogen into electricity and heat, with water as a byproduct. Indeed, when produced from renewable resources by electrolysis, hydrogen has a carbon free use cycle and allows reducing greenhouse gas emissions. As an energy vector, it can be stored in different forms, directly consumed as a fuel in internal combustion engines or considered as an energy source to generate electricity. Several technologies of FC exist, among them Proton Exchange Membrane FC (PEMFC). Thanks to its fast and easy start-up, its high power density and low temperature operation, PEMFCs are perfect candidates for both stationary and transport applications. However, performance, safety and reliability of PEMFCs have to be improved to extend their large-scale commercialization. Because FC is multi-physics in nature, and FC systems require numerous ancillaries, many faults can occur as sensors and actuators

* Corresponding author. Tel.: +262 (0)262 938223; fax: +262 (0)262 938673.

E-mail addresses: carole.lebreton@univ-reunion.fr (C. Lebreton), michel.benne@univ-reunion.fr (M. Benne), cedric.damour@univ-reunion.fr (C. Damour), nadia.steiner@univ-fcomte.fr (N. Yousfi-Steiner), brigitte.grondin@univ-reunion.fr (B. Grondin-Perez), daniel. hissel@univ-fcomte.fr (D. Hissel). 


\begin{tabular}{|c|c|}
\hline \multicolumn{2}{|c|}{ Nomenclature } \\
\hline $\mathrm{RH}$ & relative humidity, \% \\
\hline $\mathrm{T}$ & temperature, ${ }^{\circ} \mathrm{C}$ \\
\hline$P$ & outlet gas pressure, $\mathrm{kPa}$ \\
\hline$\dot{m}$ & mass flow rate, sccm \\
\hline I & load current, $\mathrm{A}$ \\
\hline $\mathrm{V}$ & measured voltage, $\mathrm{V}$ \\
\hline$\widehat{\mathrm{V}}$ & voltage estimated by neural network, $\mathrm{V}$ \\
\hline$\Delta P$ & measured cathodic pressure drop, $\mathrm{kPa}$ \\
\hline$\widehat{\Delta P}$ & $\begin{array}{l}\text { cathodic pressure drop estimated by neural } \\
\text { network, } \mathrm{kPa}\end{array}$ \\
\hline $\mathrm{J}$ & cost function \\
\hline$s_{V}$ & voltage acceptance threshold, \% \\
\hline$s_{\triangle P}$ & $\begin{array}{l}\text { cathodic pressure drop acceptance threshold, } \\
\mathrm{kPa}\end{array}$ \\
\hline \multicolumn{2}{|c|}{ Greek letters } \\
\hline$\lambda$ & gas excess ratio \\
\hline$\theta$ & neural network weight matrix \\
\hline$\varphi$ & neural network activation function \\
\hline$\varepsilon_{\mathrm{V}}$ & $\begin{array}{l}\text { relative error between simulated and measured } \\
\text { voltage, \% }\end{array}$ \\
\hline$\varepsilon_{\Delta \mathrm{P}}$ & $\begin{array}{l}\text { error between simulated and measured } \\
\text { cathodic pressure drop, } \mathrm{kPa}\end{array}$ \\
\hline \multicolumn{2}{|c|}{ Subscripts } \\
\hline $\mathrm{a}$ & anode \\
\hline c & cathode \\
\hline cell & fuel cell \\
\hline air & air \\
\hline set & setpoint \\
\hline \multicolumn{2}{|c|}{ Controller parameters } \\
\hline u & manipulated variable \\
\hline y & controller output \\
\hline$y_{\text {set }}$ & controller setpoint \\
\hline$e$ & trajectory tracking error \\
\hline$n_{y}$ & number of past outputs required \\
\hline$n_{u}$ & number of past inputs required \\
\hline$k_{c}, \tau_{i}$ & PID controller parameters \\
\hline
\end{tabular}

failures, or improper operating conditions. The safety and the reliability of the system require a high tolerance to these malfunctions.

In the best-case scenario, these malfunctions lead to performance losses. At worst, system failures, irreversible degradations and premature ageing can occur. Basics classical controllers are not able to manage these faults. Their weaknesses induce productivity, performance and reliability losses due to control loop inefficiency. A control strategy which tolerates system faults by maintaining suitable operating conditions is then needed. In this context, fault tolerant control strategies (FTCS) allow to fulfill industrial expectations despite of these possible faults. FTCS is highly developed to control safety-critical systems, and increasingly to satisfy industrial expectations. FTCS avoids incidents, maintains stability, ensures safety, reliability and system efficiency despite of possible faults [1]. FTCS could be an efficient way to improve FC availability and also FC lifetime, that are not yet fully optimal for industrial applications.

FTCS can be sorted into 2 types: passive and active FTCS, respectively PFTCS and AFTCS. The PFTCS design relies on a controller expected to be robust against some specific presumed faults. These faults, assumed to be known a priori, are only taken into account during controller synthesis. Controller parameters will not be adjusted anymore after this stage and its tolerance is limited to these expected faults. Regarding PFTCS, neither FDI tools nor reconfiguration mechanisms are needed. On the contrary, AFTCS typically includes a Fault Detection and Isolation tool (FDI), which diagnoses the fault thanks to physical (additional hardware sensors) or analytical (soft sensors) redundancy. The fault diagnosis result is sent to a reconfiguration mechanism. This tool determines the remedial actions to be started or calculates the appropriate parameters to reconfigure the controller. The previous FDI tool allows setting up the appropriate response to each specific fault.

Both passive and active FTCS have advantages and limitations, as exposed in Ref. [2]. Because of FDI tool implementation requires redundancy an active FTCS is more complex to develop than a passive strategy. Furthermore, the AFTCS effectiveness strongly depends on FDI tool efficiency. However, even if PFTCS is simpler to implement and to perform, its tolerance to faults declines as the number of expected faults increases. Besides, from performance point of view, PFTCS is designed to be robust against a list of predefined faults without any consideration about the optimal performance for any of these faults conditions. Basically, AFTCS components are: a diagnosis tool, a reconfiguration mechanism and an adjustable controller. Because these components involved really different fields and approaches, the development of these tools were conducted separately and independently. For FC applications, each AFTCS components have already been tested and validated separately, making AFTCS implementation easier to carry out.

FC diagnosis tools can be sorted in two main categories: model-based and non-model-based approaches. In literature, many FC diagnosis tools have been investigated.

A complete study on non-model-based approaches has been conducted in Ref. [3], describing the three types of approaches: artificial intelligence, statistical and signal processing methods.

Model-based methods are often residual-based, they involve the instantaneous remoteness between the real FC behavior and the expected optimal and healthy behavior. A model describing a healthy FC system behavior is identified and the residue between this model and the collected experimental data is calculated. The residue analysis allows detecting and isolating faults. There are as many FC models as residual-based diagnosis methods. As examples, the models can be Artificial Neural Networks (ANN), equivalent circuits or based on physical equations. A thorough survey of modelbased diagnosis is done in an overview [4].

In addition to an FC stack or a single cell, an FC system requires a various number of ancillaries to operate (Fig. 1). These ancillaries include hydrogen storage, gas flow controllers, gas humidification systems, temperature and pressure 


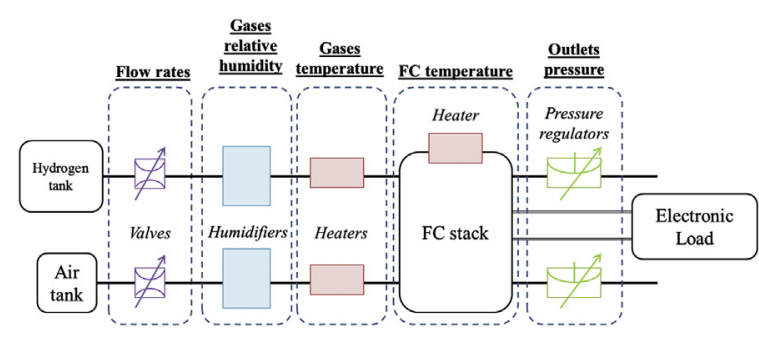

Fig. 1 - FC system scheme.

management systems, an electrical power converter, as well as sensors and control equipment. To ensure a proper operation of the FC system, all of these ancillaries have to be correctly controlled. The diversity of these ancillaries forces the investigation of different FC control strategies based on several approaches. FC control approaches are widely present in literature. Among others, a Nonlinear Model-based Predictive Control (NMPC) of the output power is validated off-line using a $10 \mathrm{~kW}$ FC stack experimental data [5] and tested online on a single PEM FC [6]. A nonlinear second order sliding mode controller is carried out through Hardware-In-Loop emulator to regulate oxygen excess ratio [7]. Adaptive controllers as self-tuning PID controller are investigated to regulate fuel cell oxygen excess ratio and are tested on-line in Ref. [8]. Flatness approach controllers are synthesized to regulate air supply [9] or membrane water content [10]. Air feed system control by an adaptive ANN based controller is performed online thanks to an FC emulator and presented in Ref. [11]. Other air supply regulations are performed by tracking the Maximum Efficiency Point in Ref. [12] or by tracking the Maximum Power Point in Ref. [13].

Even if FC controllers and FDI tools are investigated and presented in literature, rare publications deal with FTCS applied to fuel cells. Ref. [14] presents an AFTCS devoted to air feeding control fault including compressor voltage and air valve opening area faults thanks to redundancy. The FDI tool is not implemented but supposed to be available and efficient. This AFTCS provides an adequate oxygen excess ratio to the FC despite of two actuators faults. A Model Predictive Controller is implemented as control loop and the AFTCS shows good capability in simulation to improve control performance and to provide a fault tolerance against compressor faults. AFTCS and PFTCS are both tested showing the superiority of AFTCS efficiency. Ref. [15] presents an FTCS for an FC/ battery hybrid bus powertrain. Three kinds of faults are detected thanks to physical and analytical redundancy. According to faults diagnosis, a decision-making part selects one of the six pre-defined actions to be undertaken to recover system performance. This decision is applied reconfiguring the control algorithm devoted to the average power demand prediction. This AFTCS shows effectiveness during experiments. Because of empirical models used in faults diagnosis, the applicability of this AFTCS is limited. Ref. [16] develops an AFTCS applied to fuel cell breathing. Tested in simulation, oxygen starvation can be avoided thanks to a switching supervisory control and a bank of two PID back-up controllers. Ref. [17] presents a fault tolerant control strategy against fault in the tractions machines, in addition to an energy management strategy for hybrid fuel cell/ultra capacitors electric vehicles. The fault tolerant control consists of a choice between two sets of currents to apply to the five-phase PMSM (Permanent Magnetic Synchronous Machines). The aim of this FTCS is to stabilize the power delivered by the FC, in order to increase FC life time, and also entire HEV (Hybrid Electric Vehicle) life time.

In the present work, a real-time AFTCS is built to prevent electrolytic membrane hydration faults. The proposed AFTCS is composed of an FDI tool, an adjustable controller and a reconfiguration mechanism. The proposed FDI tool is a residual-based diagnosis tool using ANN models. This approach is appropriate to real-time diagnosis thanks to a low computational time. The adjustable controller integrated to the proposed FTCS approach is a neural model-based selftuning PID controller. Due to its high robustness against model uncertainties and low computational time, it appears to be a suitable candidate to be used as reconfigurable controller module.

This work is articulated as follow: the Section 2 describes the experimental conditions. The third section presents the FTCS design. FTCS experimental results on flooding fault are shown in Section 4. Last, Section 5 depicts conclusion and perspectives.

\section{Experimental description}

\section{PEM FC assembly}

In this study, the FTCS validation is carried out on a singlecell, consisting of a $50 \mathrm{~cm}^{2}$ active area Membrane Electrode Assembly (MEA) and bipolar plates. The MEA is commercialized by Paxitech and includes a membrane (made of Nafion ${ }^{\odot}$ 115) and two symmetric electrodes (made of Pt-doped carbon black deposited onto carbon felt). The FC assembling is composed of the MEA, the gaskets and the bipolar plates, clamped together after torque optimization. The bipolar plates are designed with four serpentines channels.

\section{Fuel cell test bench}

The used test bench is designed by Fuel Cell Technologies. A whole test bench description can be found in a previous work [8]. Most of operating conditions can be set and monitored, as FC temperature, gas dew point temperatures, gas flow rates and outlet pressures. An electronic load allows controlling FC current density or output voltage. These variables are managed by a LabVIEW-based Supervisory Control Data Acquisition (SCDA) system.

The FTCS is developed in MatLab ${ }^{\odot}$ environment. The control actions are applied to the FC system thanks to communication between MatLab ${ }^{\odot}$ and the SCDA system, as shown in Fig. 2.

\section{Experimental operating conditions}

Healthy and flooding experiments are carried out through operating conditions control. Several operating conditions 


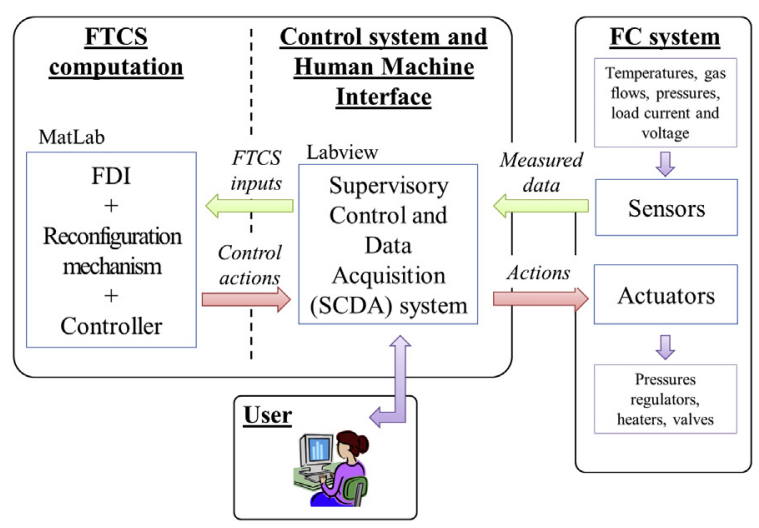

Fig. 2 - Scheme of interactions between the control strategy and the FC system.

influence the FC hydration level as gas relative humidity levels $\mathrm{RH}_{\mathrm{a} / \mathrm{c}}$, gas flow rates, $\mathrm{FC}$ temperature $\mathrm{T}_{\text {cell }}$, outlet gas pressures $\mathrm{P}_{\mathrm{a} / \mathrm{c}}$, FC design and current density. In this study, flooding is simulated experimentally by applying a low oxygen excess ratio $\lambda_{\mathrm{O}_{2}}$ as shown in Fig. 3. Firstly, from that time, the evolution of voltage curve and of cathode pressure drop curve results from $\lambda_{\mathrm{O}_{2}}$ change. Then, in a second step, the evolutions result from flooding process as shown in Fig. $3 b$ and $c$.

The $\lambda_{\mathrm{O}_{2}}$ effect on voltage and cathode pressure drop is well known. On the one hand, a low $\lambda_{\mathrm{O}_{2}}$ causes a low oxygen concentration in gas diffusion layer, and fuel cell voltage output declines. On the other hand, $\lambda_{\mathrm{O}_{2}}$ decreasing during a constant current operation corresponds to a reduction of air flow rate $\dot{m}_{\text {air }}$, which reduces proportionally cathode pressure drop.
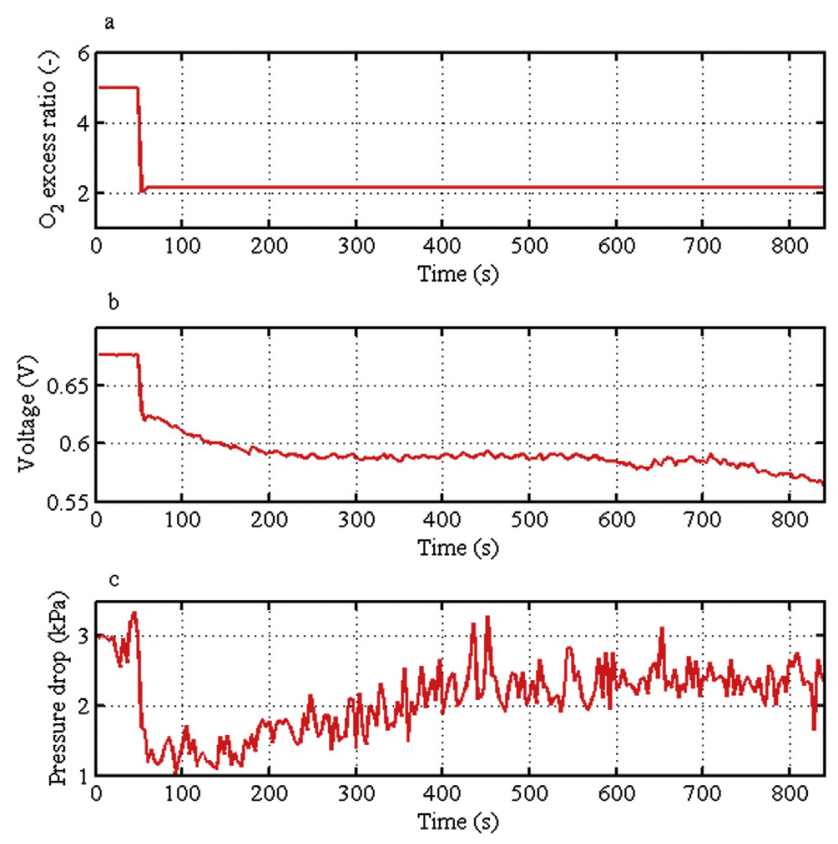

Fig. 3 - Flooding process: (a) oxygen excess ratio, (b) Voltage output and (c) cathode pressure drop curves during flooding experiments.
Notice that cathode pressure drop reacts instantaneously to air mass flow modification, while voltage declines slower, presumably because of diffusion phenomenon.

Flooding is an accumulative complex mechanism. A complete description of flooding mechanism and its effect on pressure drop can be found in Ref. [18]. Liquid water inside the channel and at gas diffusion layer surface is not evaporated or evacuated due to improper operating conditions as low gas flow or low FC temperature which favor water condensation and accumulation. The water droplets size increases gradually by coalescence phenomenon. These water droplets obstruct gas diffusion layer pores and block the reactant gas crossing to the active layer. This process leads to voltage decrease. Furthermore, the water droplets formation reduces the channel cross section area, leading to cathode pressure drop increase.

$\lambda_{\mathrm{O}_{2}}$ values are determined as 5 and 2, respectively during healthy and flooding operating conditions. The operating conditions are kept constant during healthy and flooding experiments as follow:

- hydrogen excess ratio $\lambda_{\mathrm{H}_{2}}$ is set at 2 ,

- FC temperature $\mathrm{T}_{\text {cell }}$ at $80^{\circ} \mathrm{C}$,

- gases relative humidity $\mathrm{RH}_{\mathrm{a} / \mathrm{c}}$ at $80 \%$,

- and pressures $\mathrm{P}_{\mathrm{a} / \mathrm{c}}$ are maintained at $300 \mathrm{kPa}$.

\section{FTCS applied to water management}

\section{Water management issues}

Hydration issues have a large impact on FC lifetime and longterm performance, as well as gas starvation, materials degradations, cell contamination and bad temperature management [19]. A review of water management issues can be found in Refs. [20-22] are reviews dedicated to flooding issues. The effects of the degradation due to water formation and transport are reviewed in Ref. [23]. A well humidified membrane is permeable to protons and has a good conductivity. A lack of water dries out the membrane and decreases the electrical FC performance, which is a reversible degradation. Nevertheless, the membrane dehydration can lead to membrane mechanical stresses. Irreversible degradations as cracks can occur and may generate a risk of gas leakage. Contrary, too much water restricts gas circulation and decreases reactants concentration in active layers. Considering industrial applications of fuel cell technology, load cycling can lead to hydration issues and associated degradations, as explained in a review of factors influencing the fuel cell lifetime during vehicles applications [24]. Moreover, the hydration/dehydration cycles decrease FC lifetime, as example by buckling phenomena [25]. The water management is studied in several works, in the aim to understand and optimize the two-phase water flow. In Ref. [26], the authors investigate the impact of stoichiometry, $\mathrm{RH}$ and temperature on the water management in the cathode channel of a single-serpentine PEMFC. A coverage ratio of water is defined thanks to direct visualization and image processing on transparent FC device. This paper includes a quite complete survey of works dealing with water management issues, flooding phenomena and accumulation of water. 
Similar work has been done to characterize water accumulation on multiple serpentines channels of a $50 \mathrm{~cm}^{2}$ PEMFC, using neutron imaging and statistical analysis [27]. The authors of [28] present a concept of PEM fuel cell with internal air flow humidification using the produced water. The concept is investigated experimentally and with a pseudo 2-D 5-segment model.

The previously cited works aim to understand water accumulation phenomenon, to quantify the amount of water inside the channels in order to address water management issues. The presented methods require visualization equipment or multi-dimensional models that are complex to develop for on-line applications. The current work proposes a systemic approach using essentially external measurements already performed. The approach consists to determine the hydration level of the fuel cell thanks to indirect method and to control water flow using operating conditions regulation.

\section{AFTCS principle}

Ensuring FC performance despite of faults occurrence as hydration issues, remains an important challenge. In this context, fault tolerant control strategies appear to be perfectly suited to tackle this challenge. A synthetic diagram of FTCS is depicted in Fig. 4, whereas the proposed AFTCS is fully detailed in Fig. 5. The FDI tool detects the faults occurrence and determines the FC State of Health ( $\mathrm{SoH})$. According to this diagnosis, a reconfiguration mechanism identifies the remedial actions to be undertaken. In case of a flooded FC, the reconfigurable mechanism set the oxygen excess value at a higher level in order to drain the water out of the channel and to recover from the flooded state.

\section{Diagnosis tool}

The diagnosis tool is residual-based. Analytical redundancy is performed to estimate hydration level indicators using a model-based approach. A mechanistic model of membrane hydration involves diphasic flux, electrochemistry and thermodynamics equations. Although these models are highly developed as shown in the full review [29], their important complexity level and high computational time limit online applications. With regard to their short computational time and their ability to model nonlinear systems as PEMFC, empirical models as ANNs have proven to be more suitable for

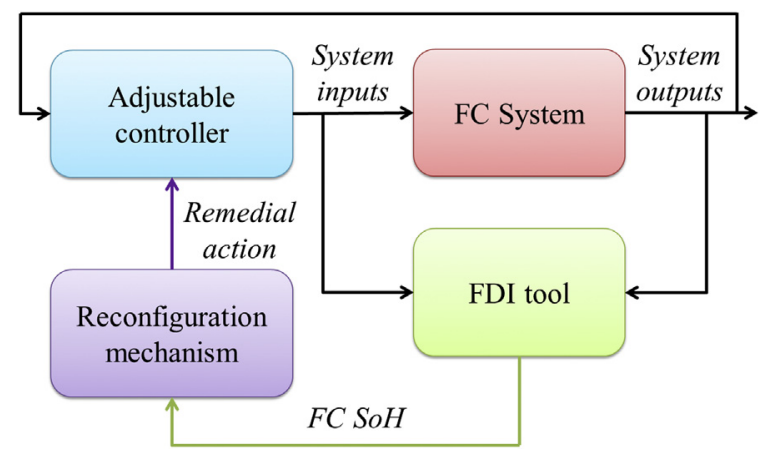

Fig. 4 - AFTCS global scheme. online applications [30]. Indeed, ANNs possess the ability to model accurately nonlinear systems as PEMFC, and have sufficiently short computational time to model online the FC behavior. Two hydration level indicators are modeled and acceptance thresholds between estimated values and experimental data are defined.

\section{ANN identification}

ANNs are here considered to simulate the behavior of a healthy FC. A residue different from 0 between the simulated and the experimental data are compared to acceptance thresholds then indicating fault appearance. The used diagnosis tool is loosely based on [31]. Output voltage and cathode pressure drop that are well known hydration level indicators [32] are used in this study. It should be noted that their monitoring is experimentally feasible and non-invasive.

As concerns dynamic modeling of a nonlinear system using ANN, identification is performed in 4 steps. First, database is collected. It needs to be relevant and adequate to represent the dynamic behavior of the system. During the second step, the ANN structure has to be selected according to the system properties. The ANN parameters, called weighting parameters, are estimated in a third step through a learning process. Finally, in fourth step, the identified ANN model is validated with different data, unused during the learning step.

Representative data. In the present case, ANN models are expected to simulate the behavior of a healthy fuel cell, under proper operating conditions, and various current and $\dot{m}_{\text {air }}$ values. Sampling time $\Delta t$ is set at $4 \mathrm{~s}$. The database is generated by successively applying different values of current and $\dot{m}_{\text {air }}$, in order to cover a wide range of the operating conditions. Randomly, current is set from $8 \mathrm{~A}$ to $12 \mathrm{~A}$, and $\dot{m}_{\text {air }}$ varies between $260 \mathrm{sccm}$ and $990 \mathrm{sccm}$, which correspond to $\lambda_{\mathrm{O}_{2}}$ values from 2 to 5 . Most of these combined operating conditions are carried out resulting in a rich in information database.

For the identification process, the database is separated into two parts: $80 \%$ devoted to the learning step, and the remaining $20 \%$ to the validation step.

Selected structure. The structure for the two ANN models is a three layers network composed of an input layer, one hidden layer and an output layer. The choice to implement a onehidden-layer structure, with a sufficient number of hidden units, also called neurons, is motivated by K. Hornik works [33]. The output layer contains one neuron. The neurons of the three layers are linked by weighted connections, stored in a matrix $\theta$.

The weighted sum of each neuron inputs is submitted to a function $\varphi$ which conditions the neuron activation. The activation functions $\varphi$ are defined as a nonlinear hyperbolic tangent function in the hidden layer, and as a linear function in the output layer.

Let $u_{(t)}$ and $y_{(t)}$ be respectively system input and output, representative of the system behavior at the instant $t$, and $\widehat{y}_{(t)}$ a model output, image of $y_{(t)}$. In the aim of real-time implementation, it has been decided that each model predicts $\widehat{y}_{(t)}$ thanks to past information at the instant $t-\Delta t$. Therefore, ANNs input layer includes the inputs $u_{(t-\Delta t)}$ and past simulated output $\widehat{y}_{(t-\Delta t)}$, as described in Fig. 6. The inputs of the two 


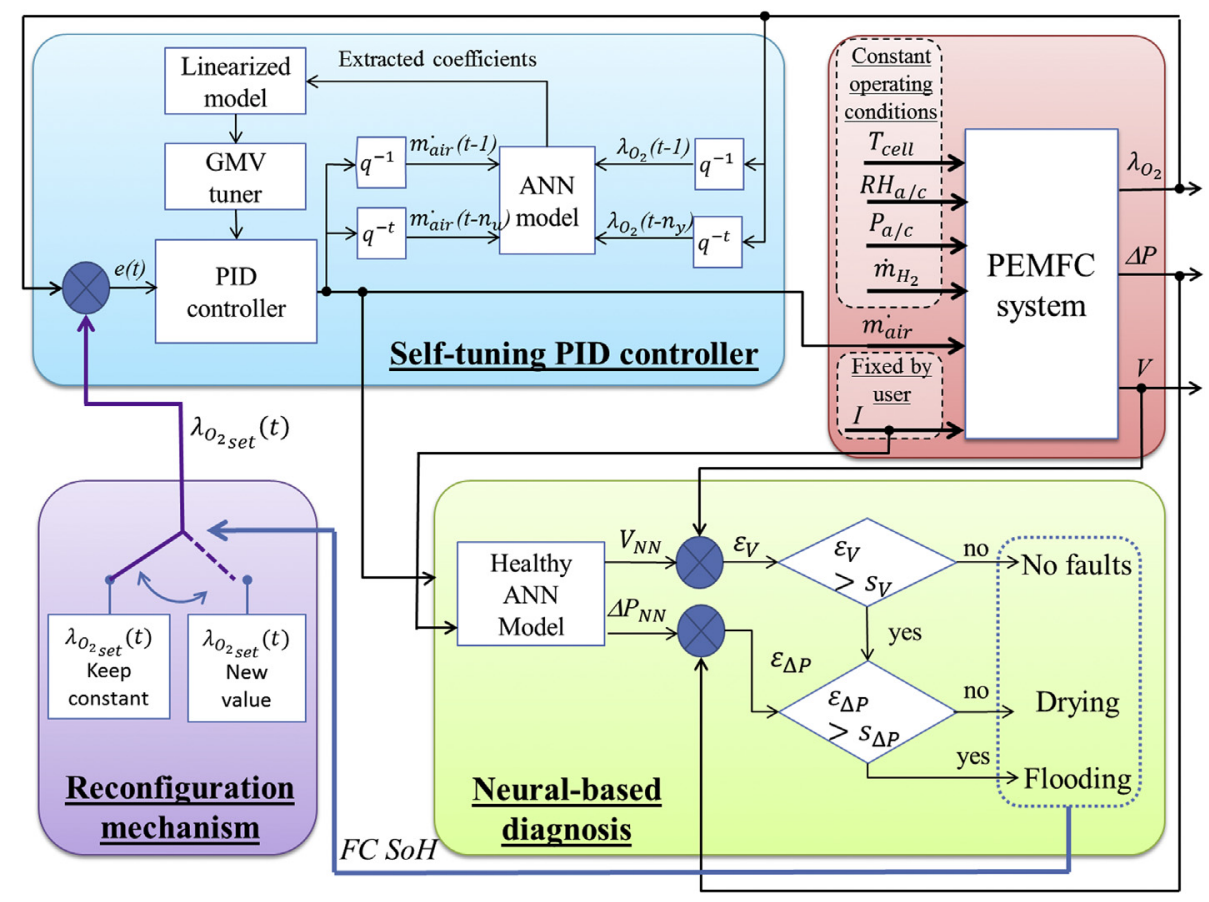

Fig. 5 - FTCS detailed scheme.
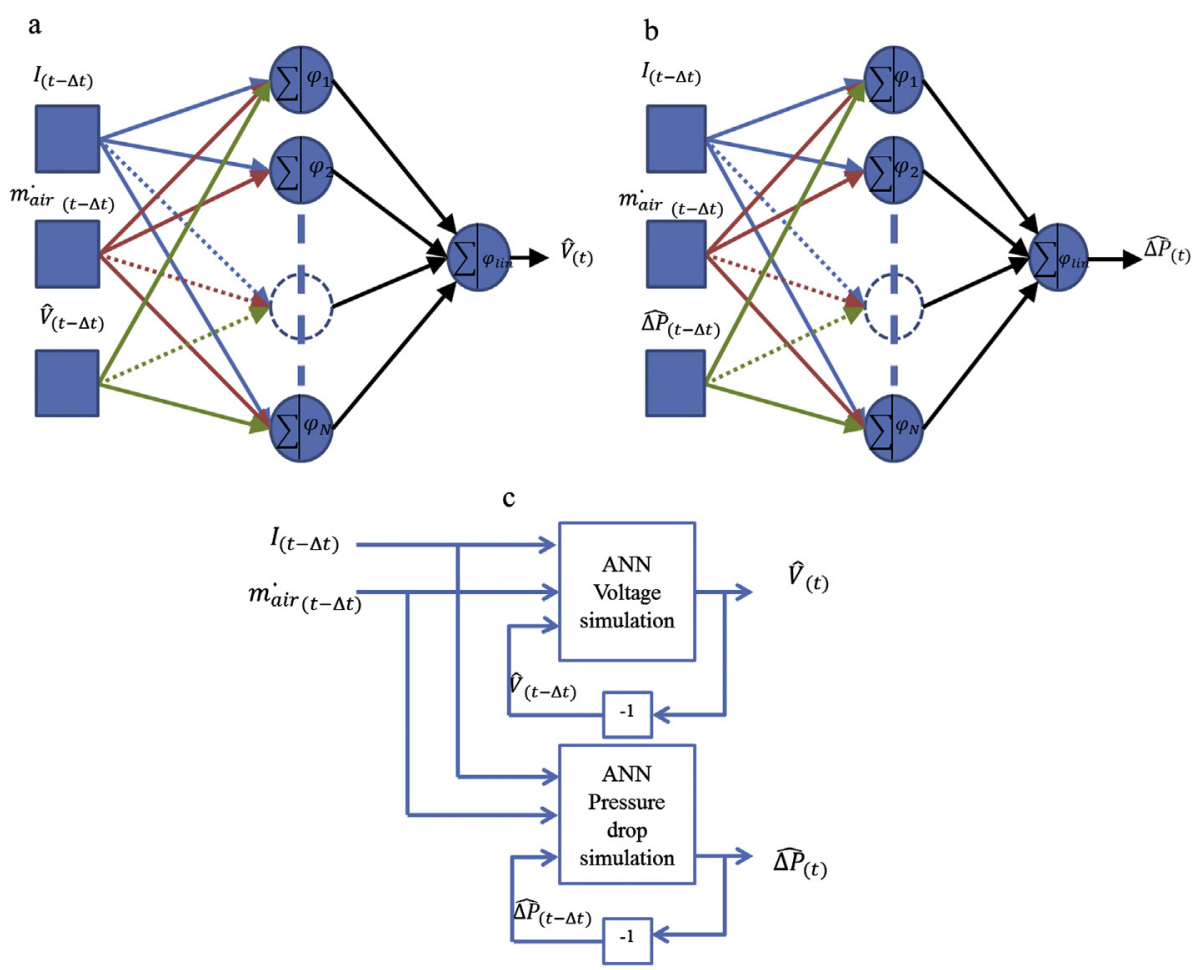

Fig. 6 - ANNs structure: (a) ANN Voltage simulation internal structure, (b) ANN Pressure drop simulation internal structure, (c) ANNs inputs/outputs scheme. 
a

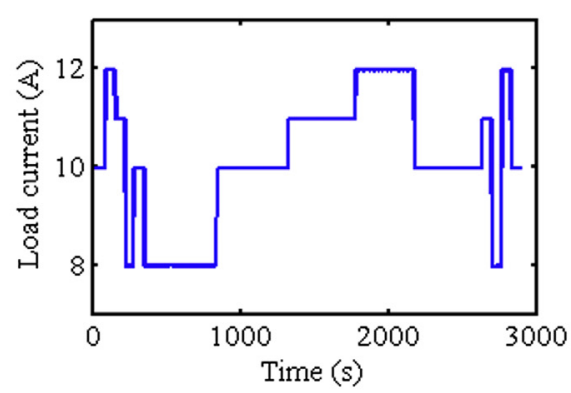

C

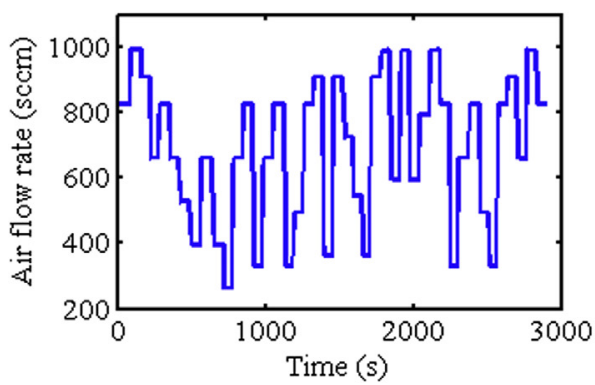

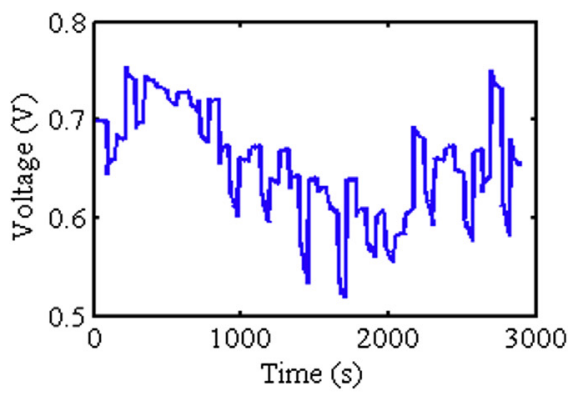

$d$

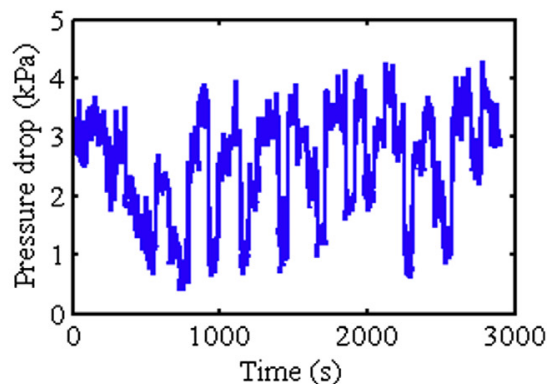

Fig. 7 - Neural networks training data: (a) load current, (b) output voltage, (c) air flow rate, (d) pressure drop.

ANNs are $\dot{m}_{\text {air }}$, load current I and regressive measurement of cathode pressure drop and output voltage.

This model is performed through a MatLab Toolbox ${ }^{\circ}$ developed by M. NØrgaard [34] which include the used function called NNARX (NoNlinear Auto Regressive with eXogenous inputs).

Learning step (parameters estimation). Thanks to $80 \%$ of the collected database (Fig. 7), the ANN models are identified meaning that the weighting parameters are estimated. The below cost function based on classical quadratic convergence criterion is optimized thanks to Levenberg-Marquardt algorithm.

$J(\theta)=\sum_{i=1}^{n}(y(t)-\widehat{y}(u(t), \theta))^{2}$

where $J(\theta)$ is the cost function, $u(t)$ and $y(t)$ the system inputs and output, $\hat{y}$ the estimated output and $\theta$ the matrix of weighting parameters.

The stopping criteria are based on a maximal number of iterations and weighting parameters variations.
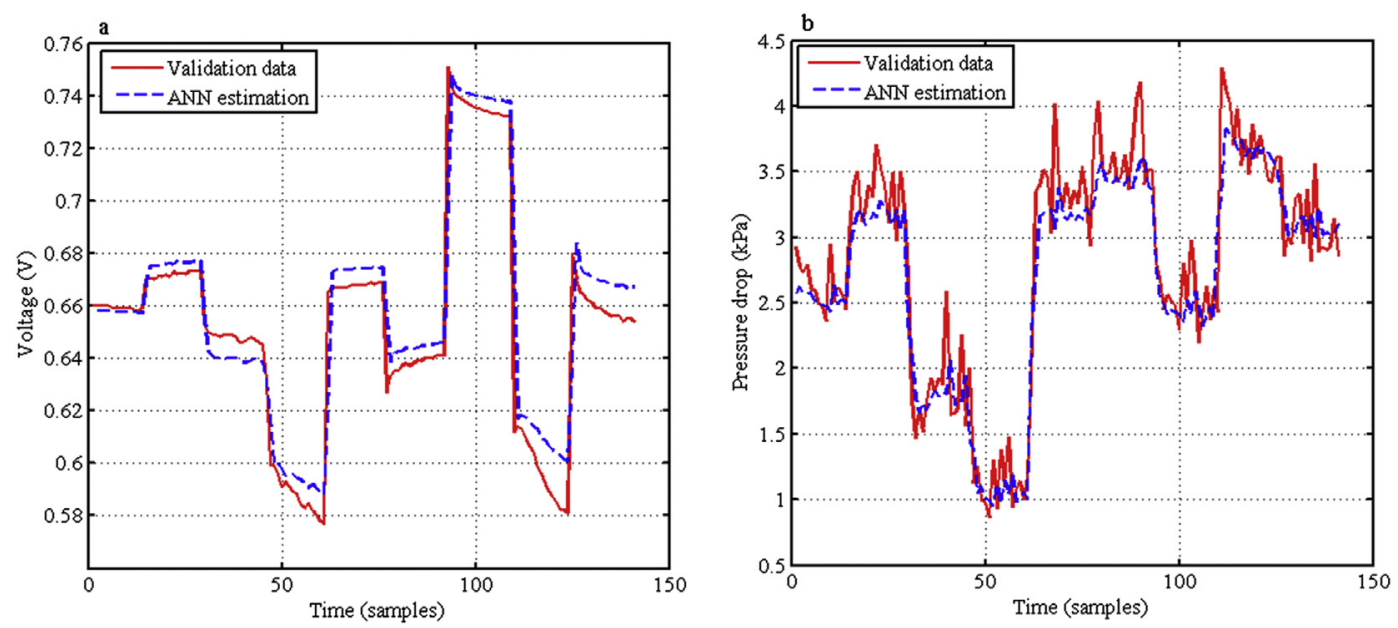

Fig. 8 - Neural networks validation step: (a) Output voltage model validation, (b) Pressure drop model validation. 
Table 1 - ANN validation results.

RMSE

MRE (\%)

\begin{tabular}{lcc}
$\begin{array}{l}\text { Output voltage } \\
\text { modeling error }\end{array}$ & 0.0119 & 0.0130 \\
$\begin{array}{l}\text { Pressure drop } \\
\text { modeling error }\end{array}$ & 0.2914 & 0.0864 \\
\hline
\end{tabular}

Validation step. The ANNs validation step is performed on 142 saved point's database and results can be seen in Fig. 8. Two criteria are used to assess the models performance: Root Mean Square Error (RMSE) and Mean Relative Error (MRE), calculated with equations (2) and (3). The results are presented in Table 1.

$R M S E=\sqrt{\frac{\sum_{i=1}^{n}\left(\widehat{y}_{i}-y_{i}\right)^{2}}{n}}$

$M R E=\frac{\sum_{i=1}^{n} \frac{\left|y_{i}-y_{i}\right|}{y_{i}}}{n}$

where $\widehat{y}_{i}$ is the simulated data, $y_{i}$ the experimental data both at sample $i$ and $n$ the number of samples.

Regarding on-line FDI purposes, the ANN models prediction performance is considered quite satisfactory.

\section{Diagnosis thresholds}

Acceptance thresholds are empirically set: $5 \%$ of relative error between ANN simulation and output voltage $\varepsilon_{V}$, and $0.50 \mathrm{kPa}$ of error between pressure drop simulation and measurement $\varepsilon_{\Delta P}$, according to the following equations (4) and (5). In case of $\varepsilon_{V}$ and $\varepsilon_{\Delta P}$ simultaneously reach their respective threshold, the experimental point is considered as flooded.

$\varepsilon_{\mathrm{V}}=\frac{\widehat{\mathrm{V}}-\mathrm{V}}{\mathrm{V}}$

$\varepsilon_{\Delta P}=\Delta P-\widehat{\Delta P}$

\section{False alarm management and reconfiguration mechanism}

Modeling errors, sensors measurements errors, or experimental uncertainties can lead the diagnosis tool to a wrong fault detection or isolation. To avoid false alarms, and FTCS inefficiency, a false alarms management strategy is needed. The principle is based on diagnosis results of a sequence of 5 successive experimental points, which corresponds to a sliding window of $20 \mathrm{~s}$. If more than a half of the points are assigned as flooded points by the diagnosis tool, the FC State of Health ( $\mathrm{SoH})$ is determined as flooded. Note that even this strategy slightly delays the trigger of the remedial action, its cost-benefits ratio is clearly positive. Indeed, a delay of few seconds is preferable to an unsuitable remedial action.

When the FC SoH is defined, the reconfiguration mechanism determines the remedial actions to be applied. This reconfiguration mechanism is based on a priori knowledge of the system. In case of flooding detection, the remedial action is defined as oxygen excess ratio setpoint $\lambda_{\mathrm{O}_{2} \text { set }}(t)$ increasing in order to drain water out of the cathodic channel.

$\lambda_{\mathrm{O}_{2} \text { set }}(\mathrm{t})$ has two pre-defined values, corresponding respectively to a low value (2) and a high value (5). The reconfiguration mechanism decides of the appropriate $\lambda_{\mathrm{O}_{2} \text { set }}(t)$ according to the FC SoH. In case of a healthy SoH, the chosen value is the low value.

In case of flooding detection, $\lambda_{\mathrm{O}_{2} \text { set }}(\mathrm{t})$ is set at the high value that is sufficiently important to recover from flooding.

\section{Control loop}

After the fault detection and isolation, the reconfiguration mechanism undertakes remedial actions. In the proposed AFTCS, the remedial action to a flooding fault is an increasing of $\lambda_{\mathrm{O}_{2}}$. Among the various controllers dedicated to $\lambda_{\mathrm{O}_{2}}$ regulation, this FTCS integrates a neural model-based self-tuning PID controller. The controller output $y(t)$ is defined as the $\lambda_{\mathrm{O}_{2}}$, $y_{\text {set }}(t)$ is the oxygen excess ratio setpoint, $e(t)$ is the trajectory tracking error and the manipulated variable $u(t)$ is the inlet air flow rate. $n_{y}$ and $n_{u}$ are respectively the number of past inputs and outputs required, $k_{c}, \tau_{i}$ and $\tau_{d}$, are the PID parameters (Fig. 5).

This self-tuning PID controller operates an updating of its parameters at each sample time, according to the operating point. Part of this controller, an ANN model simulates the FC behavior. The instantaneous linearization of this model output is coupled to a General Minimum Variance (GMV) law, allowing online PID parameters updating. The optimal parameters are calculated thanks to a cost function minimization detailed in Refs. [8], implemented thanks to a not iterative procedure.

The proposed controller demonstrated highly satisfactory results in terms of setpoint tracking ability and disturbances rejection capability, regardless of the operating conditions. It has also proven to have good robustness properties against plant/model mismatch. The experimental validation of the self-tuning PID controller and its complete description can be consulted in Ref. [8].

\section{Results}

The FCTS, implemented in Matlab ${ }^{\odot}$ environment, is executed on-line to communicate with the SCDA of the test bench, as explain in Section 2.2 Fuel cell test bench.

Fig. 9 shows a sequence of online FTCS tests. Four successive flooding and recoveries steps can be noticed during the experiment. A flooding step can be clearly defined as voltage decreasing and pressure drop increasing.

The operating conditions are maintained as described in Section 2.3 Experimental operating conditions. Fig. 9a shows the output voltage evolution during the experiment and Fig. 9c describes cathode pressure drop. Fig. 9b draws the voltage losses estimation and the corresponding threshold of $5 \%$. During constant current mode, this value could represent the estimated power losses. Fig. 9d represents the residue between healthy and experimental cathode pressure drop and the corresponding threshold determined at $0.5 \mathrm{kPa}$.

The first part of experimental procedure corresponds to a sequence of current from 0 to $396 \mathrm{~s}$, in healthy operating conditions. $\lambda_{\mathrm{O}_{2}}$ is imposed at an appropriate value of 5 . Current is consecutively set at 11, 8 and $10 \mathrm{~A}$. After the third steps of current, the current is set at $10 \mathrm{~A}$ and kept constant. This part 

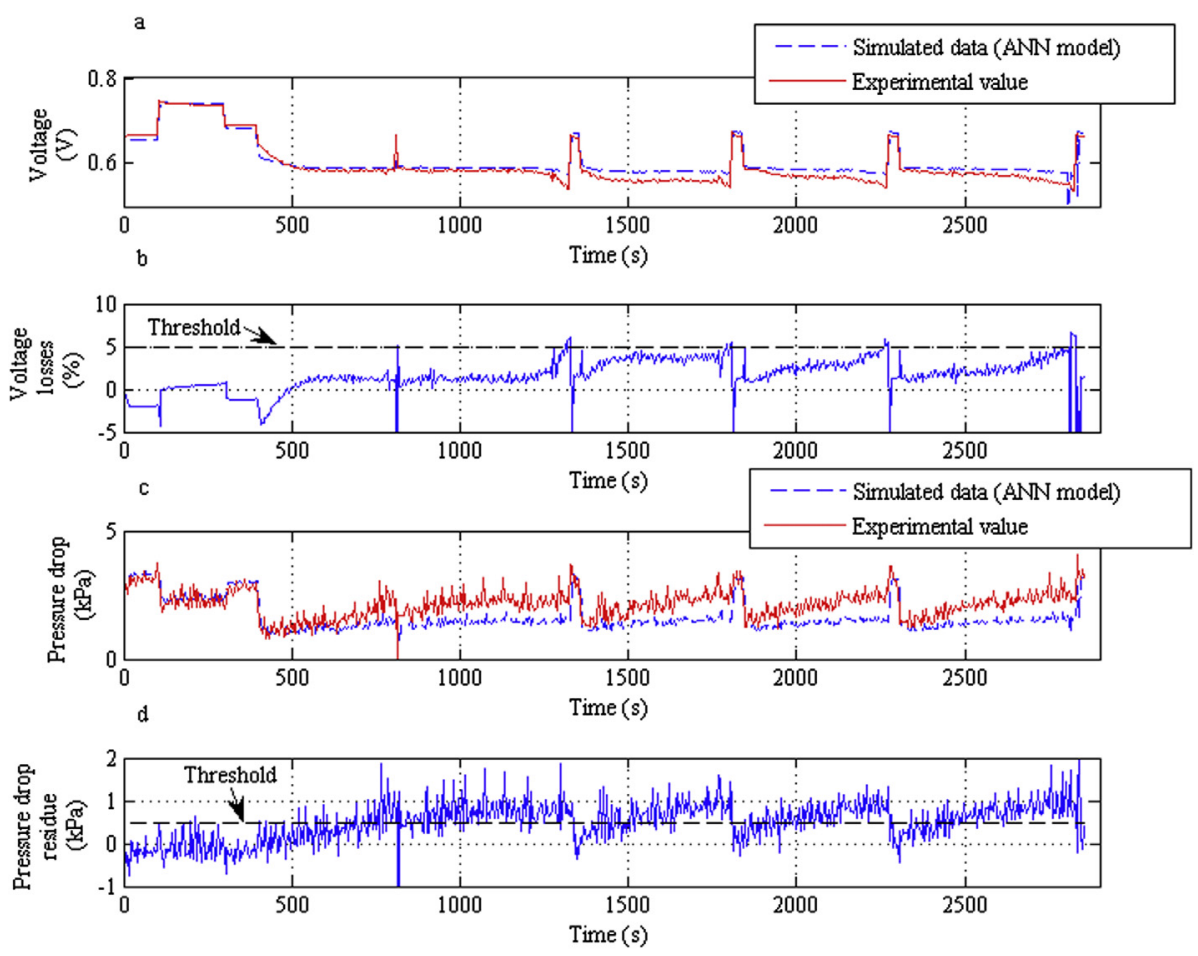

Fig. 9 - Experimental FTCS results: (a) voltage measurement and ANN simulation during flooding and recoveries, (b) output voltage losses and associated threshold, (c) pressure drop measurement and ANN simulation (d) pressure drop residue and associated threshold.

of the experimental protocol aims to validate the model describing a healthy behavior during a healthy operation. As shown in Fig. 9a. simulated voltage is close to experimental data even if a small modeling error is noticeable. Fig. 9b. highlights the importance of the determination of the thresholds. The modeling error is below the $5 \%$ threshold of fault detection, and no false alarms can occur. An important voltage threshold allows reducing the effect of modeling error on diagnosis accuracy. Cathode pressure drop simulation is accurate, as shown in the first part of Fig. 9c.

The second step begins by an abrupt reduction of $\lambda_{\mathrm{O}_{2}}$ at time $396 \mathrm{~s}$. At a current of $10 \mathrm{~A}$, flooding is induced by reducing $\lambda_{\mathrm{O}_{2}}$, meaning $\dot{m}_{\text {air }}$ is abruptly reduced. The current is maintained at $10 \mathrm{~A}$.

As expected and described in a previous part, the decrease in $\lambda_{\mathrm{O}_{2}}$ induces first voltage and pressure drop decreasing. Fig. 9c shows that cathode pressure drop rises, reaches the threshold and settles at a high value. Fig. 9b and Fig. 9d show that $\varepsilon_{\Delta \mathrm{P}}$ reaches the pressure drop error threshold whereas $\varepsilon_{\mathrm{V}}$ remains below voltage error threshold. Output voltage settles and keeps constant for a while before decreasing and $\varepsilon_{V}$ reaches the voltage error threshold. Then the fault is detected and identified at $1324 \mathrm{~s}$, the $\mathrm{SoH}$ is defined as flooded and thanks to the reconfiguration mechanism, the $\lambda_{\mathrm{O}_{2}}$ controller setpoint is adjusted to recover an appropriate hydration level and FC performance. $\lambda_{\mathrm{O}_{2}}$ setpoint is increased from 2 to 5 during $24 \mathrm{~s}$. During the recovery step, $\varepsilon_{\Delta \mathrm{P}}$ and $\varepsilon_{\mathrm{V}}$ drop below the acceptance threshold. The FC is estimated as again in healthy SoH by the FDI tool.
After the $24 \mathrm{~s}$ of recovery step, the $\lambda_{\mathrm{O}_{2}}$ setpoint is reduced at 2 , to be back to favorable conditions for flooding. Residues are below the acceptance thresholds, the $\mathrm{SoH}$ is still defined as healthy. As flooding is in progress, it can be seen on Fig. $9 \mathrm{~b}$ and $c$ that residues are increasing during $450 \mathrm{~s}$ before reaching the thresholds again. Throughout the experiment, flooding issues are detected at 1324 s, 1804 s, 2268 s and 2824 s. Note that the recovery step does not allow retrieving initial FC voltage when $\lambda_{\mathrm{O}_{2}}$ returns to its initial value. Nevertheless, Fig. 9a shows that after three corrections in a row, the output voltage tends to reach the simulated voltage. Fig. 9b clearly shows that as corrections are made, the voltage residue remains longer close to 0 before reaching again the threshold. It could be an indication that the recovery step does not last long enough to drain all liquid water out of the FC.

In an effort to optimize the recovery step characteristics, a study considering the amplitude and the duration of the $\lambda_{\mathrm{O}_{2}}$ plateau is in progress, assessing their impact on the retrieval performance.

Note that cathode pressure drop allows detecting flooding $400 \mathrm{~s}$ before output voltage decline and performance losses. In case of flooding, monitoring only pressure drop as described in Ref. [35] could prevent faults earlier than associating output voltage as second indicator.

\section{Conclusion and perspectives}

In this paper, a real-time implementable AFTCS dedicated to PEMFC water management has been developed and 
validated on-line on a real FC. The proposed AFTCS comprises an FDI tool to determine the FC SoH, a reconfiguration mechanism to decide of the appropriate remedial actions, and an adjustable controller to fulfill the $\lambda_{\mathrm{O}_{2}}$ setpoint based on FC SoH.

In a first stage, a residual-based diagnosis tool has been designed to determine on-line the state of health of the fuel cell. In this aim, analytical redundancies on FC output voltage and cathode pressure drop have been built thanks to ANN models. In a second stage, based on this diagnosis, a reconfiguration mechanism determines the remedial actions. In case of flooding, $\lambda_{\mathrm{O}_{2} \text { set }}(\mathrm{t})$ is updated. According to this updated setpoint, a self-tuning PID controller calculates the inlet air flow rate. Besides, to improve the reliability of the proposed AFTCS, a false alarm management method has been designed. Eventually, to assess the performance of the proposed strategy, the AFCTS has been implemented on-line and validated on a test bench.

The proposed AFTC demonstrated excellent efficiency in terms of diagnosis and recovery performance. Experimental results show that flooding was detected once voltage losses and cathode pressure drop values reached acceptance thresholds. Indeed, power losses could have been limited at $5 \%$ thanks to FTCS online implementation, and the membrane hydration level could have been controlled through $\lambda_{\mathrm{O}_{2}}$. In this manner, the FTCS efficiently prevented important flooding and high performance losses. This strategy improves performance stability and FC reliability.

The presented results are encouraging for recovering from flooding issues, thanks to easy-to-implement Fault Tolerant Control Strategy. However, the FDI tool efficiency is highly dependent of the empirical thresholds selection. In future works, the empirical thresholds optimization according to operating conditions or FC ageing could be a great research challenge. Moreover, the use of empirical models restricts the applicability of the proposed strategy and collecting adequate training data to identified ANN models can be complex and time consuming. To overcome these limitations, further works are currently in progress to substitute the model-based FDI tool by a non-model based one.

\section{Acknowledgments}

This work is funded by the European Social Fund and the Réunion Region.

\section{R E F E R E N C E S}

[1] Zhang Y, Jiang J. Bibliographical review on reconfigurable fault-tolerant control systems. Annu Rev Control 2008;32:229-52. http://dx.doi.org/10.1016/ j.arcontrol.2008.03.008.

[2] Jiang J, Yu X. Fault-tolerant control systems: a comparative study between active and passive approaches. Annu Rev Control 2012;36:60-72. http://dx.doi.org/10.1016/ j.arcontrol.2012.03.005.

[3] Zheng Z, Petrone R, Péra MC, Hissel D, Becherif M, Pianese C, et al. A review on non-model based diagnosis methodologies for PEM fuel cell stacks and systems. Int J Hydrogen Energy 2013;38:8914-26. http://dx.doi.org/10.1016/ j.ijhydene.2013.04.007.

[4] Petrone R, Zheng Z, Hissel D, Péra MC, Pianese C, Sorrentino $\mathrm{M}$, et al. A review on model-based diagnosis methodologies for PEMFCs. Int J Hydrogen Energy 2013;38:7077-91. http://dx.doi.org/10.1016/ j.ijhydene.2013.03.106.

[5] Damour C, Benne M, Kadjo J-JA, Rosini S, Grondin-Perez B. Fast NMPC scheme of a $10 \mathrm{~kW}$ commercial PEMFC. Int J Hydrogen Energy 2013;38:7407-13. http://dx.doi.org/10.1016/ j.ijhydene.2013.04.019.

[6] Ziogou C, Papadopoulou S, Georgiadis MC, Voutetakis S. Online nonlinear model predictive control of a PEM fuel cell system. J Process Control 2013;23:483-92. http://dx.doi.org/ 10.1016/j.jprocont.2013.01.011.

[7] Matraji I, Laghrouche S, Jemei S, Wack M. Robust control of the PEM fuel cell air-feed system via sub-optimal second order sliding mode. Appl Energy 2013;104:945-57. http:// dx.doi.org/10.1016/j.apenergy.2012.12.012.

[8] Damour C, Benne M, Lebreton C, Deseure J, Grondin-Perez B. Real-time implementation of a neural model-based selftuning PID strategy for oxygen stoichiometry control in PEM fuel cell. Int J Hydrogen Energy 2014;39:12819-25. http:// dx.doi.org/10.1016/j.ijhydene.2014.06.039.

[9] Da Fonseca R, Bideaux E, Gerard M, Jeanneret B, DesboisRenaudin M, Sari A. Control of PEMFC system air group using differential flatness approach: validation by a dynamic fuel cell system model. Appl Energy 2014;113:219-29. http:// dx.doi.org/10.1016/j.apenergy.2013.07.043.

[10] Damour C, Benne M, Grondin-Perez B, Chabriat J-P, Pollet BG. A novel non-linear model-based control strategy to improve PEMFC water management - the flatness-based approach. Int J Hydrogen Energy 02/2015;40(5):2371-6. http://dx.doi.org/ 10.1016/j.ijhydene.2014.12.052.

[11] Sanchez VM, Barbosa R, Arriaga LG, Ramirez JM, Ingenier D, Roo UDQ, et al. Science direct real time control of air feed system in a PEM fuel cell by means of an adaptive neuralnetwork. Int J Hydrogen Energy 2014;39:16750-62. http:// dx.doi.org/10.1016/j.ijhydene.2014.05.153.

[12] Bizon N. Tracking the maximum efficiency point for the FC system based on extremum seeking scheme to control the air flow. Appl Energy 2014;129:147-57. http://dx.doi.org/ 10.1016/j. apenergy.2014.05.002.

[13] Becherif M, Hissel D. MPPT of a PEMFC based on air supply control of the motocompressor group. Int J Hydrogen Energy 2010;35:12521-30. http://dx.doi.org/10.1016/ j.ijhydene.2010.06.094.

[14] Puig V, Feroldi D, Serra M. Fault-tolerant MPC control of PEM fuel cells. In: 17th world congr IFAC; 2008. p. 11112-7.

[15] Xu L, Li J, Ouyang M, Hua J, Li X. Active fault tolerance control system of fuel cell hybrid city bus. Int J Hydrogen Energy 2010;35:12510-20. http://dx.doi.org/10.1016/ j.ijhydene.2010.08.005.

[16] Ari I, Ricardo SSP. Using the unfalsified control concept to achieve fault tolerance. In: 17th world congr int fed autom control; 2008. p. 1236-42. http://dx.doi.org/10.3182/200807065-KR-1001.00213.

[17] Aouzellag H, Ghedamsi K, Aouzellag D. Energy management and fault tolerant control strategies for fuel cell/ultracapacitor hybrid electric vehicles to enhance autonomy, efficiency and life time of the fuel cell system. Int J Hydrogen Energy 2015;40:7204-13. http://dx.doi.org/10.1016/ j.ijhydene.2015.03.132.

[18] Song M, Pei P, Zha H, Xu H. Water management of proton exchange membrane fuel cell based on control of hydrogen pressure drop. J Power Sources 2014;267:655-63. http:// dx.doi.org/10.1016/j.jpowsour.2014.05.094. 
[19] Schmittinger W, Vahidi A. A review of the main parameters influencing long-term performance and durability of PEM fuel cells. J Power Sources 2008;180:1-14. http://dx.doi.org/ 10.1016/j.jpowsour.2008.01.070.

[20] Yousfi-Steiner N, Moçotéguy P, Candusso D, Hissel D, Hernandez A, Aslanides A. A review on PEM voltage degradation associated with water management: impacts, influent factors and characterization. J Power Sources 2008;183:260-74. http://dx.doi.org/10.1016/ j.jpowsour.2008.04.037.

[21] Li H, Tang Y, Wang Z, Shi Z, Wu S, Song D, et al. A review of water flooding issues in the proton exchange membrane fuel cell. J Power Sources 2008;178:103-17. http://dx.doi.org/ 10.1016/j.jpowsour.2007.12.068.

[22] Mason TJ, Millichamp J, Neville TP, Shearing PR, Simons S, Brett DJL. A study of the effect of water management and electrode flooding on the dimensional change of polymer electrolyte fuel cells. J Power Sources 2013;242:70-7. http:// dx.doi.org/10.1016/j.jpowsour.2013.05.045.

[23] Ous T, Arcoumanis C. Degradation aspects of water formation and transport in proton exchange membrane fuel cell: a review. J Power Sources 2013;240:558-82. http:// dx.doi.org/10.1016/j.jpowsour.2013.04.044.

[24] Pei P, Chen H. Main factors affecting the lifetime of proton exchange membrane fuel cells in vehicle applications: a review. Appl Energy 2014;125:60-75. http://dx.doi.org/ 10.1016/j.apenergy.2014.03.048.

[25] Uchiyama T, Kato M, Yoshida T. Buckling deformation of polymer electrolyte membrane and membrane electrode assembly under humidity cycles. J Power Sources 2012;206:37-46. http://dx.doi.org/10.1016/ j.jpowsour.2012.01.073.

[26] Bozorgnezhad A, Shams M, Kanani H, Hasheminasab M, Ahmadi G. The experimental study of water management in the cathode channel of single-serpentine transparent proton exchange membrane fuel cell by direct visualization. Int J
Hydrogen Energy 2015;40:2808-32. http://dx.doi.org/10.1016/ j.ijhydene.2014.12.083.

[27] Iranzo A, Boillat P, Biesdorf J, Tapia E, Salva A, Guerra J. Liquid water preferential accumulation in channels of PEM fuel cells with multiple serpentine flow fields. Int J Hydrogen Energy 2014;39:15687-95. http://dx.doi.org/10.1016/ j.ijhydene.2014.07.101.

[28] Tolj I, Bezmalinovic D, Barbir F. Maintaining desired level of relative humidity throughout a fuel cell with spatially variable heat removal rates. Int J Hydrogen Energy 2011;36:13105-13. http://dx.doi.org/10.1016/j.ijhydene.2011.07.078.

[29] Siegel C. Review of computational heat and mass transfer modeling in polymer-electrolyte-membrane (PEM) fuel cells. Energy 2008;33:1331-52. http://dx.doi.org/10.1016/ j.energy.2008.04.015.

[30] Grondin-Perez B, Roche S, Lebreton C, Benne M, Damour C, Kadjo J-J. mechanistic model versus artificial neural network model of a single-Cell PEMFC. Engineering 2014;6:418-26. http://dx.doi.org/10.4236/eng.2014.68044.

[31] Yousfi Steiner N, Hissel D, Moçotéguy P, Candusso D. Diagnosis of polymer electrolyte fuel cells failure modes (flooding \& drying out) by neural networks modeling. Int J Hydrogen Energy 2011;36:3067-75. http://dx.doi.org/10.1016/ j.ijhydene.2010.10.077.

[32] Barbir F, Gorgun H, Wang X. Relationship between pressure drop and cell resistance as a diagnostic tool for PEM fuel cells. J Power Sources 2005;141:96-101. http://dx.doi.org/ 10.1016/j.jpowsour.2004.08.055.

[33] Hornik K. Approximation capabilities of muitilayer feedforward networks. Neural Netw 1991;4:251-7.

[34] Nørgaard M. Neural network based system identification toolbox. Version 2. 2000.

[35] Steiner NY, Candusso D, Hissel D, Moçoteguy P. Model-based diagnosis for proton exchange membrane fuel cells. Math Comput Simul 2010;81:158-70. http://dx.doi.org/10.1016/ j.matcom.2010.02.006. 